\title{
Construction Sequence Based Influence of High-rise Urban Development on Pedestrian Wind Comfort in Lujiazui, Shanghai
}

\author{
Jia-Wei YAO ${ }^{1, a}$, Feng YANG ${ }^{2, b}$, Zhi ZHUANG ${ }^{3, c}$ and Feng YUAN ${ }^{4, d, *}$ \\ ${ }^{1,2,3,4}$ Built Environment Technology Center, College of Architecture and Urban Planning, Tongji \\ University, No. 1239 Siping Rd, Shanghai, 200092, China \\ ajiawei.yao@tongji.edu.cn, byangfeng@tongji.edu.cn, ${ }^{c} 13585880473 @ 139 . c o m,{ }^{d}$ philipyuan007@t \\ ongji.edu.cn \\ ${ }^{*}$ Corresponding author
}

Keywords: Construction Sequence, Urban Development, Pedestrian Wind Comfort, Lujiazui.

\begin{abstract}
Pedestrian wind comfort is becoming an important factor of evaluating the urban quality, because it influences the urban micro-climate, heat island effect, building energy consumption and the vitality of the city, especially in high-density and high-rise areas. This paper has selected one typical district - Lujiazui Central Business District (CBD), with a large number of skyscrapers, for analyzing the relationship among urban physical data, construction sequence and outdoor wind environment. Firstly, Computational Fluid Dynamics (CFD) has been applied to simulate the outdoor natural ventilation in different development stages in Lujiazui district. Then, pedestrian wind comfort will be evaluated, which integrated with the fourth dimension (buildings' construction completion time) for regression analysis. This research results will provide the government and designers feasible urban design recommendation for establishing sustainable outdoor urban environment.
\end{abstract}

\section{Introduction}

The quality of the available open spaces can influence the quality of life within cities, and isolation and social exclusion may be exacerbated if the quality of such spaces is poor or unacceptable [1]. This relates to the physical properties of the space (including micro-climates, thermal properties, visual and acoustic comfort levels, and urban morphology) as well as the social environment. According to recent research, the micro-climate of a given outdoor urban space is therefore of significance to the way the space is used and the activities that are carried out, because thermal, and by implication comfort, conditions affect people's decisions and behaviours in terms of utilising outdoor spaces [2].

The creation of low air velocity spaces surrounding tall buildings may give rise to a poor outdoor wind environment in summer conditions. In these conditions, the wind velocity not only has a desirable maximum but also a minimum condition in order to create the acceptable and comfortable wind velocity range that allows better urban life at the pedestrian level. With this in mind, it suggest that the modification of wind patterns in a built-up area due to neighbouring buildings could be quite significant [3]. Interference effects depend on several conditions: (a) upstream obstacles and terrain conditions; (b) the morphology and arrangement of adjacent constructions; and (c) the angle between structures' orientations and the prevailing wind direction. As well wind velocity being impacted by the level of aerodynamic interference, the effects may extend to affect the efficiency of building ventilation systems, wind loads, air quality, and pedestrian comfort.

In recent years, the economy and urban structure of Shanghai has developed at a significantly high speed, and the Lujiazui district has been designed to become one of the most dominating international financial centres in the world, a development model that has been copied by many other Chinese cities. Therefore, urban and architectural design are accepted as effective methods of easing the UHI (urban heat island), which reduces indoor energy consumption by offering a better and healthier outdoor environment $[4,5]$. Thus, environmentally aware urban planning and building designs are definitely important. The unique urban fabric, in terms of its street patterns, building heights, open 
spaces, density, features, landscape and so on, should inform and determine the environmental quality both within buildings and outside of them.

\section{Study Area}

This section introduces the development model of the outdoor wind environment over the past 20 years in Lujiazui district. 41 tall buildings were constructed in this area over the last 20 years and, based on their structure completion time, they are divided into eight groups. The first high building is Shanghai Oriental Pearl TV Tower completed in 1994, while the most recent is the Shanghai Tower which was completed in 2014 (Fig. 1).

There are eight models representing the development of the initial environment without tall buildings to the current one with high buildings wherein the wind environment will be simulated on the pedestrian level. Following the simulation, the development of the pedestrian wind environment will be analyzed via an air ventilation assessment to determine the amount of outdoor space that meets the wind comfort criteria. According to the previous local pedestrian thermal comfort research, under the condition of the highest frequency range of global radiation and air temperature, the outdoor $\mathrm{WV}_{\text {winter }}$ should be below $3.2 \mathrm{~m} / \mathrm{s}$ to be comfortable and acceptable to pedestrians. The outdoor thermal comfort questionnaire survey was not done in Shanghai in summer, but the wind comfort criteria can reference to other related research that has similar climatic conditions and residents' requirements. Ng recommended that the pedestrian level wind velocity should be above 1 to $2 \mathrm{~m} / \mathrm{s}$ so as to supply sufficient outdoor ventilation on hot, calm days in Hong Kong [4]. Consequently, the Hong Kong Building Environmental Assessment Method (HK-BEAM) requires that there are no stagnant areas that have a wind speed less than $1.5 \mathrm{~m} / \mathrm{s}$ [5]. Both Hong Kong and Shanghai have a high temperature in summer (approximately $30^{\circ} \mathrm{C}$ of average temperature) and are typical high density lots of tall building districts, thus the minimum WV is applicable in Shanghai. Therefore, the Soligo research team specified that the threshold of pedestrian wind comfort is $5 \mathrm{~m} / \mathrm{s}$ of wind speed [6]. To assess the outdoor wind environment in summer, the comfortable and acceptable $\mathrm{WV}_{\text {summer }}$ range in Shanghai can be set at $2 \mathrm{~m} / \mathrm{s}$ to $5 \mathrm{~m} / \mathrm{s}$ in this study.
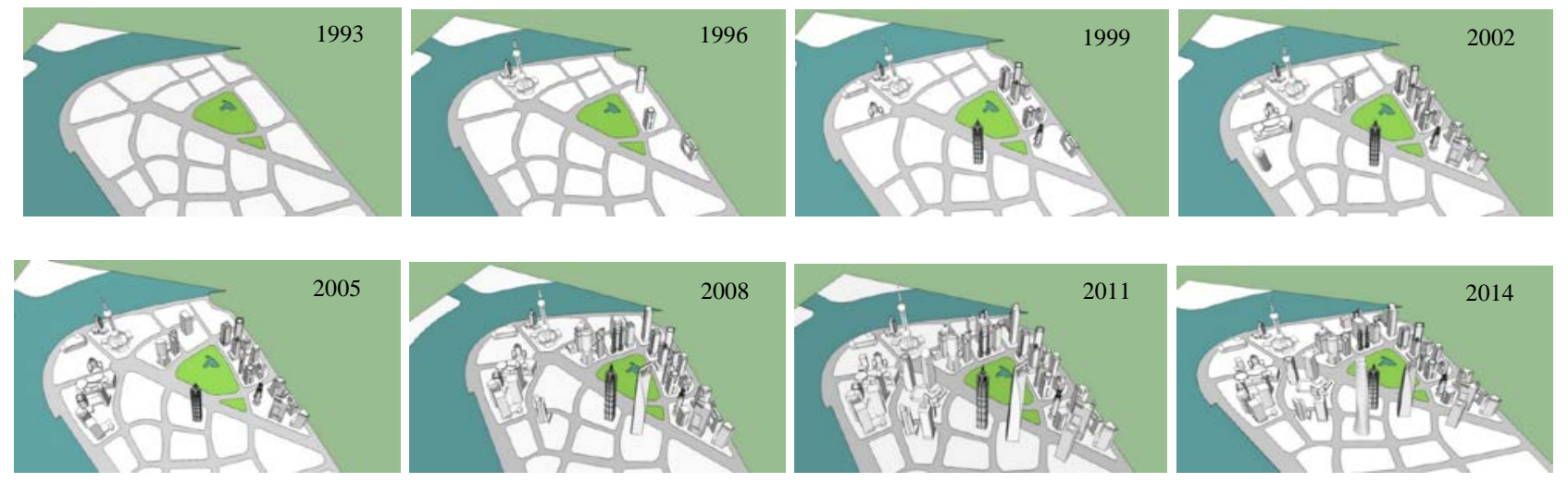

Fig. 1 The development of tall buildings in Lujiazui, Shanghai

\section{Methods}

A CFD simulation of the wind environment around tall buildings in 2014, which includes the geometry and domain settings, in FlowDesigner can be applied to different stages of development to plan future urban design. Figure 5 shows the tall buildings which receive specific attention in this paper. The area of the tall buildings is approximate $1400 \mathrm{~m} * 1100 \mathrm{~m}$, while their average height is approximately $260 \mathrm{~m}$ and the highest building is $632 \mathrm{~m}$. Under the limitation of the software and capacity of the computer, a larger boundary size always brings more grids if the same cell size or larger cell size is kept at the same total number. Anyway, any one of them requires a longer time to 
mesh and for calculation. In this study, the dimension of the whole computational boundary is set as L $* \mathrm{~W} * \mathrm{H}=4700 * 5000 * 900 \mathrm{~m}$, which is significantly larger than other models applied in most research also focusing on outdoor wind environments.

To obtain a better and more accurate wind environment at pedestrian level, and, considering the maximum limit of the cells when they mesh, the horizontal planes were divided into a $360 * 360$ grid, while the vertical zone was divided into 60 parts. Consequently, each cell had dimensions of $13 * 13$ * 15m. However, accordance with the AIJ guidelines [7], three vertical cell layers with a height below $1.5 \mathrm{~m}$ were added because the pedestrian level is the main research target area. The mean wind velocity of each cell could be obtained from the centre of the cell, therefore, a $3 \mathrm{~m}$ high cell is conducive to gathering the more accurate results from the calculations. Furthermore, the horizontal plane is divided into two parts: the central part of interested site (high-dense grids) and the boundary (low-dense grids), while the vertical is divided into three parts: the pedestrian level (highest-dense grids); the buildings level from $3 \mathrm{~m}$ to $200 \mathrm{~m}$ (secondary-dense grids) and the boundary level above 200m (low-dense grids). The computational grid used for this research are 8,164,800 cells (360* 360 * 63) for the domain. Therefore, measured from the meteorological station in the Pudong International Airport, Shanghai, two main wind directions and their velocities have been applied in this study: WNW, $5 \mathrm{~m} / \mathrm{s}$ in winter and SSE, $5.3 \mathrm{~m} / \mathrm{s}$ in summer.

\section{Results}

The influence of developing urban morphology on the outdoor wind environment at the pedestrian level varies based on the buildings' size, location, orientation, distance, arrangement, height difference etc. With the time sequence and development of tall buildings, a pairwise comparison of outdoor air flow between two time periods in Lujiazui will be described and evaluated. Furthermore, the following independent variables are included in the multiple regression models based on: (a) RBS: the ratio of built-up area to site area; (b) TNBH: total new building heights; (c) TBH: total building heights; (d) average building heights (ABH); and (e) RCS: the ratio of wind comfort area to site area.

Based on the construction of tall buildings in the Lujiazui district between 1996 and 2014 and corresponding simulated outdoor wind environment at pedestrian level, a series of parameters regarding urban terrain, building morphology and wind comfort were selected to identify the internal relationship (Table 1). Indeed, the RCS_winter is referring to the wind comfort speed range of $0-3.2 \mathrm{~m} / \mathrm{s}$ in winter, while RCS_summer is applying the range of $2-5 \mathrm{~m} / \mathrm{s}$ in summer. Therefore, Eq. 1 and Eq. 2 describes the linear relation between RCS and other variables in both winter and summer.

Table 1 Wind environment statistics with development of tall buildings in Lujiazui

\begin{tabular}{|c|c|c|c|c|c|c|}
\hline Year & RBS, \% & TNBH, $m$ & TBH, m & ABH, $m$ & RCS_winter, \% & RCS_summer, \% \\
\hline 1996 & 3.5 & 999 & 999 & 199.8 & 7.7 & 3.4 \\
\hline 1999 & 6.8 & 1370 & 2369 & 182.2 & 20.3 & 10.3 \\
\hline 2002 & 9.5 & 1662 & 4031 & 183.2 & 26.8 & 16.7 \\
\hline 2005 & 14.1 & 527 & 4558 & 182.3 & 28.3 & 18.6 \\
\hline 2008 & 17.8 & 2091 & 6649 & 201.5 & 30.5 & 20.4 \\
\hline 2011 & 19.4 & 1449 & 8098 & 202.5 & 43.1 & 20.8 \\
\hline 2014 & 19.5 & 632 & 8730 & 212.9 & 43.3 & 21.3 \\
\hline
\end{tabular}

$$
\begin{gathered}
\mathrm{RCS}_{\text {winter }}=59.908-2.631 \mathrm{RBS}-0.255 \mathrm{ABH}+0.012 \mathrm{TBH}-0.004 \mathrm{TNBH} \\
\mathrm{RCS}_{\text {summer }}=46.492+0.471 \mathrm{RBS}-0.235 \mathrm{ABH}+0.002 \mathrm{TBH}
\end{gathered}
$$

However, the wind comfort at pedestrian level is related to the total building heights in the site, which is described in Fig. 2. It can be predicted from Eq.3 and Eq.4, with more and higher tall 
buildings in the district, the surrounding wind environment will be improved at street level, and more spaces with comfortable winds emerge in winter and summer. In addition, there are several points that are worthy of note: (a) with the growth of TBH, both RCS_winter and RCS_summer show an increasing trend; (b) the influence of higher total building heights appears more significant in winter; (c) from 2002 to 2005, significant increasing of TBH does not bring high growth of RCS, because these new established buildings have a small footprint that cannot influence air flow too much at the pedestrian level; and (d) in 2014, RCS_winter is much higher than RCS_summer, which is not because of its increase since 2011, but the final result of the cumulative difference.

$$
\begin{aligned}
& \mathrm{RCS}_{\text {winter }}=2 * 10^{-10} \mathrm{TBH}^{3}-3 * 10^{-6} \mathrm{TBH}^{2}+0.0175 \mathrm{TBH}-6.6861 \\
& \mathrm{RCS}_{\text {summer }}=3 * 10^{-11} \mathrm{TBH}^{3}-9 * 10^{-7} \mathrm{TBH}^{2}+0.0083 \mathrm{TBH}-4.3567
\end{aligned}
$$

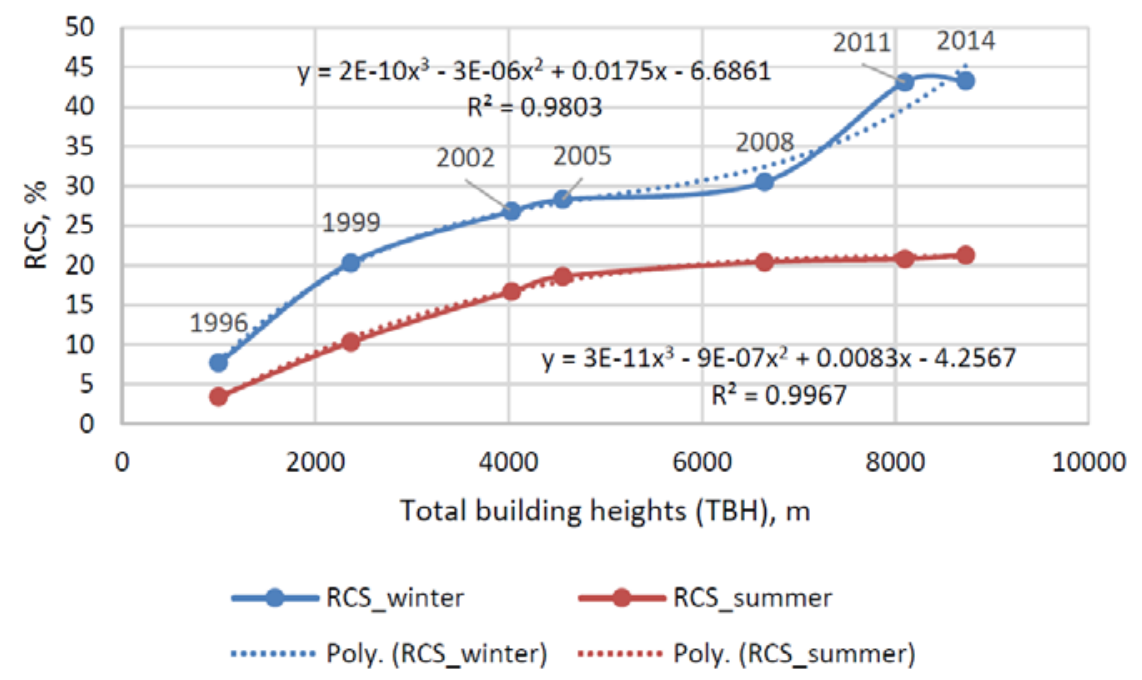

Fig 2 Relationship between TBH and RCS

As an important parameter in urban design, RBS plays a significant role in improving the RCS (Fig. 3). More buildings means less outdoor spaces for pedestrian applications, particularly as wide podiums cover a considerable area and have a significant effect on the air flow. From regression equation Eq. 5 and Eq.6, it is interesting that the RCS in winter is always higher than summer, and both develop gradually from approximately $9 \%$ to $17 \%$ of the RBS, which means the outdoor wind comfort changed slightly between 2002 and 2008. However, when the Shanghai Tower was completed in 2014, the RCS in winter increased dramatically.

$$
\begin{aligned}
& \mathrm{RCS}_{\text {winter }}=0.035 \mathrm{RBS}^{3}-1.2293 \mathrm{RBS}^{2}+14.349 \mathrm{RBS}-29.592 \\
& \text { RCSsummer }=0.0051 \mathrm{RBS}^{3}-0.2614 \mathrm{RBS}^{2}+4.764 \mathrm{RBS}-10.558
\end{aligned}
$$




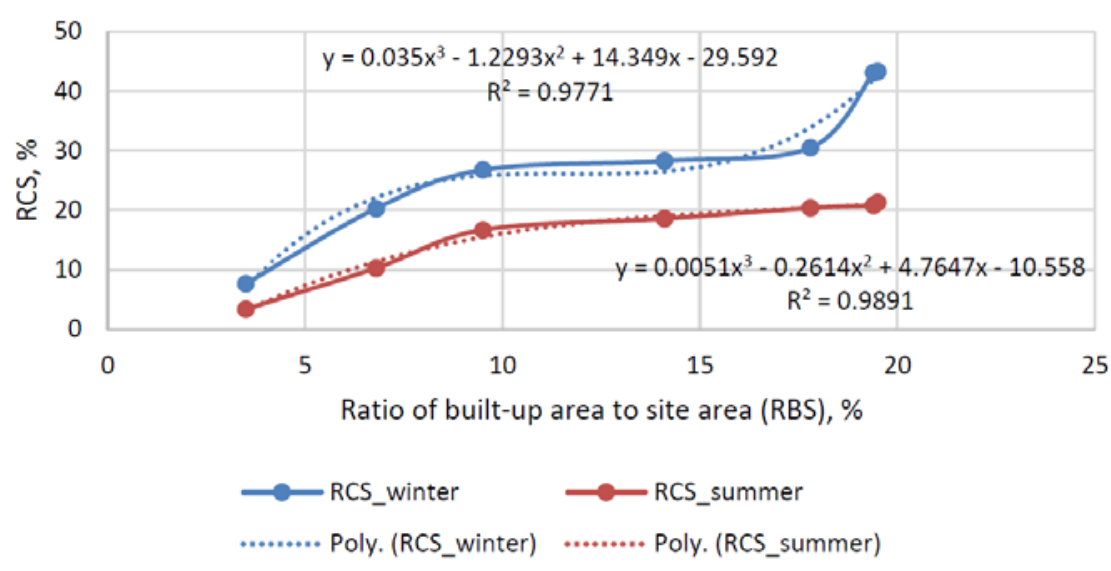

Fig 3 Relationship between RBS and RCS

\section{Conclusions and Discussion}

Air movement over urban morphology is much more complex in high density districts with many tall buildings, because the roughness of the surface may impose a frictional drag. Understanding the past and present outdoor ventilation environment is conducive to analyzing the air flow in deep street canyons and generating a more pedestrian-friendly wind environment in the future. The tall buildings have been listed with their heights and grouped by their completion time in this paper. The computational parametric approach was applied to evaluate the influence of various urban morphology, with a time period of every three years, on the outdoor natural wind environment at the pedestrian level through a CFD simulation. The discussion focused on the prevailing summer and winter winds. The simulated wind environment is analyzed and integrated with the corresponding wind comfort criteria.

Therefore, considering the building development in the Lujiazui district and its effect on the wind environment for local pedestrians, the following conclusions can be drawn regarding the future urban design:

- Total new building heights do not have strong correlation with the outdoor comfortable and acceptable wind area at pedestrian level;

- The wind comfort at pedestrian level is related to the total building heights on the site, and it appears to be more significant in winter;

- RBS also plays significant role in improving the RCS, and the size of the podium can have a massive effect; and

- The outdoor wind comfort improved slightly between 2002 and 2008 in winter and summer.

\section{Acknowledgment}

This research was financially supported by the National Natural Science Foundation of China (Grant No.51578378), the Special Funds for State Key R\&D Program during the 13th Five-year Plan Period of China (Grant No.2016YFC0702104), the Sino-German Scientific Research Program (Grant No.GZ1162) and Science and Technology Commission of Shanghai Municipality (Grant No.16dz1206502, 16DZ2250500 and 17DZ1203405).

\section{References}

[1] H. Boumaraf, A. Tacherift, Thermal comfort in outdoor urban spaces, J. Studies in Mathematical Sciences, 6, (2012) 279-283.

[2] G. Gan, CFD Simulation for Sustainable Building Design, in: R. YAO (ed.), Design and Management of Sustainable Built Environments. Springer, London, 2013 
[3] A. D. Feffeira, A. C. M. Sousa, D. X. Viegas, Prediction of building interference effects on pedestrian level comfort, J. Wind Engineering and Industrial Aerodynamics, 90, (2002) 305-319.

[4] E. Ng, V. Cheng, Urban human thermal comfort in hot and humid Hong Kong, J. Energy and Buildings, 55, (2012) 51-65.

[5] H. Wu, F. Kriksic, Designing for pedestrian comfort in response to local climate, J. Wind Engineering and Industrial Aerodynamics, 104-106, (2012) 397-407.

[6] M. J. Soligo, P. A.Irwin, C. J. Williams, G. D. Schuyler, A comprehensive assessment of pedestrian comfort including thermal effects, J. Wind Engineering and Industrial Aerodynamics, 77-78, (1998) 753-766.

[7] Y. Tominaga, A. Mochida, R. Yoshie, H. Kataoka, T. Nozu, M. Yoshikawa, T. Shirasawa, AIJ guidelines for practical applications of CFD to pedestrian wind environment around buildings, J. Wind Engineering and Industrial Aerodynamics, 96, (2008) 1749-1761. 